\title{
Flow Diverters in the Treatment of Pediatric Cerebrovascular Diseases
}

\author{
(D). Barburoglu and (D) A. Arat
} O* $=$

\begin{abstract}
BACKGROUND AND PURPOSE: There is very limited data concerning utilization of flow diverters in children. Our aim is to report results for the treatment of complex intracranial aneurysms and carotid cavernous fistulas by using flow diverters in children.
\end{abstract}

MATERIALS AND METHODS: Retrospective review of children (17 years of age or younger) treated with flow diverters between May 2011 and July 2014 was performed. Clinical and laboratory data and angiographic findings were extracted. Seven patients $(6$ males, 1 female; mean age, 12.7 years; range, 3-16 years) were included. Two presented with posttraumatic fistulas. The remaining patients presented with traumatic aneurysms of the cavernous carotid artery or fusiform aneurysms of the distal vertebral artery, M1, or A2 segments. All patients were premedicated with clopidogrel ( $75 \mathrm{mg}$ daily for patients with body weights of $>45 \mathrm{~kg}, 37.5 \mathrm{mg}$ daily for 1 small child with a body weight of $<45 \mathrm{~kg}$ ) and aspirin ( $300 \mathrm{mg}$ daily for $\geq 45 \mathrm{~kg}, 100 \mathrm{mg}$ daily for smaller children).

RESULTS: VerifyNow and Multiplate Analyzer values were higher than expected. No clinical complications were noted. Imaging performed at 7-52 months after the procedure (mean/median, 22.3/14 months) revealed occlusions of all aneurysms and fistulas. One patient had an asymptomatic occlusion of the parent artery; otherwise, no hemodynamically significant parent artery restenosis was observed. There were no clinically significant neurologic events during follow-up.

CONCLUSIONS: Although flow-diverter placement appears to be safe and effective on midterm follow-up in children, longer follow-up is critical. The current sizes of flow diverter devices and delivery systems cover the pediatric size range, obviating developing flow diverters specific to children.

ABBREVIATIONS: $\mathrm{APT}=$ antiplatelet therapy; $\mathrm{CCF}=$ carotid cavernous fistula; $\mathrm{PRU}=\mathrm{P} 2 \mathrm{Y} 12$ receptor reaction unit

$\mathrm{T}$ he introduction of flow diverters into endovascular practice has been defined by some authors as a paradigm shift. ${ }^{1}$ Currently, a significant proportion of intracranial aneurysms in adults are successfully treated with flow diverters. However, there are few case reports on the use of flow diverters in the pediatric population..$^{2-11}$ In this retrospective study, we report our experience with of flow diverters in 5 children with intracranial aneurysms and 2 children with carotid cavernous fistulas (CCFs). Through a review of our patient data and the relevant literature, we also summarize the current antiplatelet regimens used for chil-

Received May 25, 2016; accepted after revision August 8.

From the Department of Radiology (M.B.), Istanbul University Medical School, Istanbul, Turkey; and Department of Radiology (A.A.), School of Medicine, Hacettepe University, Ankara, Turkey.

Please address correspondence to Anil Arat, MD, Department of Radiology, School of Medicine, Hacettepe University, Sihhiye, Ankara, Turkey; e-mail: anilarat@hotmail.com

- Indicates open access to non-subscribers at www.ajnr.org

三 Indicates article with supplemental on-line tables.

http://dx.doi.org/10.3174/ajnr.A4959 dren undergoing cerebrovascular interventions involving the placement of stents and flow diverters. There is a need for the development of a standardized antiplatelet therapy protocol for children undergoing cerebrovascular interventions involving the placement of permanent vascular scaffolds.

\section{MATERIALS AND METHODS Patient Population}

We retrospectively reviewed our records to identify patients 17 years of age or younger who were treated by the senior author with implantation of a flow-diverter stent between May 2011 and July 2014. Clinical findings, angiographic findings, and follow-up data were extracted from our electronic hospital information system.

\section{General Description of the Endovascular Procedure}

All endovascular procedures were performed with the patients under general anesthesia. A 6F 90-cm-long sheath introducer was inserted through the common femoral artery for patients older than 4 years ( 6 patients), and a 5F long sheath introducer was used only for patients younger than 4 years of age. After insertion of the 

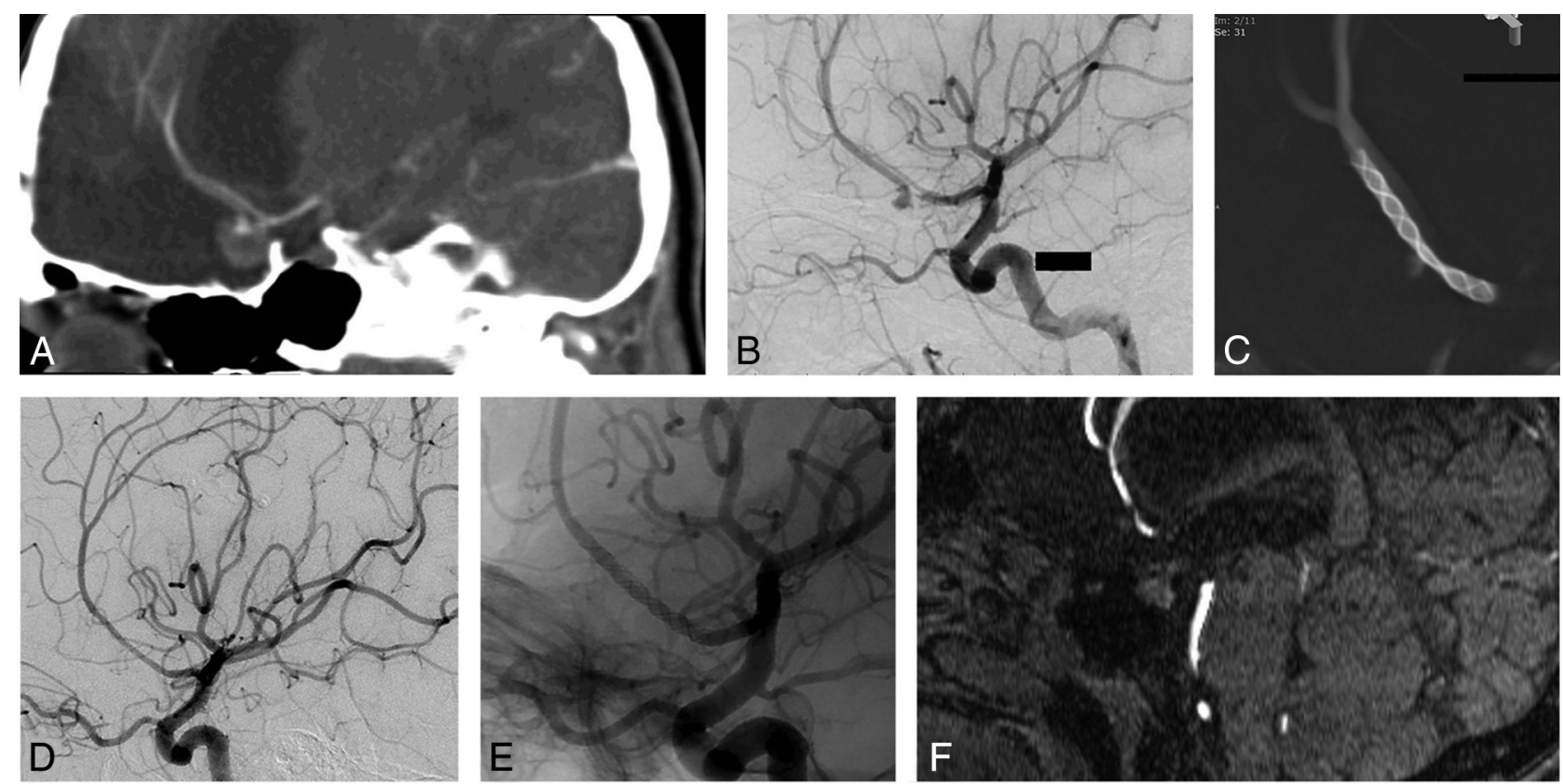

FIG 1. A, An aneurysm of the A2 segment of the right anterior cerebral artery is demonstrated on sagittal reformations of a cranial CT angiogram in a 14-year-old girl who sustained a traumatic brain injury approximately 10 years ago. The aneurysm is partially clotted and measures $10 \mathrm{~mm}$ in its largest dimension. $B$, Lateral view of the right common carotid arteriogram verifies partial opacification of the aneurysm dome. There is a stenosis of the parent artery proximal to the aneurysm, suggesting that the aneurysm is dissecting/traumatic in nature. C, Flat panel CT scan obtained during administration of diluted contrast medium intra-arterially shows that the Silk flow diverter (Balt Extrusion, Montmorency, France) totally covers the aneurysmal segment, and it is constrained at the level of the stenosis of the proximal A2 segment. D and E, Subtracted and native views of a 6-month follow-up angiogram reveal that the aneurysm is no longer opacified, the parent artery is patent, and the stenosis of the parent artery has disappeared. $F, A$ noncontrast MRA of the head obtained at 42 months shows that the patency of the parent artery is maintained and the size of the aneurysm has decreased significantly, consistent with the healing of the aneurysm.

introducer, $100 \mathrm{IU} / \mathrm{kg}$ of heparin was intravenously administered in a bolus dose; then, a heparin infusion was initiated to maintain an activated clotting time of around twice the baseline value. In all cases, a long introducer sheath was used to catheterize the common carotid or subclavian artery. A distal access catheter was placed through this sheath into the petrous segment of the targeted internal carotid arteries or the V2 segment of the vertebral artery.

For aneurysm treatment, flow diverters were deployed using previously described techniques ${ }^{12-14}$ after meticulous measurement of the parent artery size at the proximal and distal segments of the aneurysm. These measurements were made on DSA images and 3D images reconstructed from rotational angiograms on workstations of biplane angiography units (Artis zee; Siemens, Erlangen, Germany). Scaffolding stents were used for ideal placement of the flow diverters and to prevent overexpansion/shortening in fusiform giant aneurysms. The devices were optimally apposed to the vessel wall by using hypercompliant intracranial balloons if necessary after deployment. Follow-up imaging included DSA at 6 months, noncontrast MRA at 12 months, and yearly MRA thereafter. In 1 patient, a 1-month DSA was obtained to rule out residual fistula.

\section{Antiplatelet Treatment and Anticoagulation}

All patients were premedicated with clopidogrel ( $75 \mathrm{mg}$ per day for patients weighing $>45 \mathrm{~kg}, 37.5 \mathrm{mg}$ per day for the 1 child of $<45 \mathrm{~kg}$ ) and aspirin (300 mg per day for children weighing $\geq 45$ $\mathrm{kg}, 100 \mathrm{mg}$ per day for smaller children) at least 5 days before endovascular treatment. Platelet reactivity to clopidogrel based on VerifyNow (Accumetrics, San Diego, California) and results of
ADP and TRAP assays (Multiplate Analyzer; Roche Diagnostics, Mannheim, Germany) were available for 6 of the 7 treatments performed. During the procedure, an intravenous bolus dose of heparin $(100 \mathrm{IU} / \mathrm{Kg})$ was administered and heparinization was continued to maintain an activated clotting time at 2-3 times the baseline value throughout the procedure. After the procedure, dual antiplatelet treatment was continued for at least 6 months. At the 6-month DSA follow-up, clopidogrel was stopped, and aspirin was maintained. In 1 patient, both clopidogrel and aspirin were discontinued after 6 months without clinical sequelae.

\section{Statistical Analysis}

All statistical analyses were performed by using SPSS software, Version 22.0 (IBM, Armonk, New York). Categoric variables were compared using the Fisher exact test. The test was used to compare the occurrence of significant adverse events in children treated for CCF versus aneurysm.

\section{RESULTS}

Seven children (6 males and 1 female; mean age, 12.7 years; range, 3-16 years) were treated with flow diverters. Two of the patients presented with posttraumatic CCFs. The CCFs were treated by using transarterial deployment of a flow diverter with coil and/or Onyx (Covidien, Irvine, California) embolization of the fistula from the venous side. Of the remaining 5 patients, 2 presented with posttraumatic aneurysms: 1 at the origin of the A2 segment of the anterior cerebral artery (Fig 1) and 1 at the M1 segment of the middle cerebral artery. Two patients presented with recurrent cavernous segment aneurysms following endovascular treatment 
of posttraumatic CCFs. Finally, 1 patient presented with a giant right vertebral artery $\mathrm{V} 4$ segment aneurysm.

Scaffolding stents were placed during the same endovascular session in 2 aneurysms. Additionally, 1 stent was placed within the flow diverter 1 month after the endovascular procedure to prevent further fish mouthing (ie, a pencil tip-like narrowing of the distal tip of the device to form a so-called "womble-nose appearance"), ${ }^{15}$ which was evident on early follow-up on MRA and plain radiographs.

Navigation of the flow diverter to the targeted arterial segment was successful in all cases, and no problems were encountered during deployment. All the procedures were well-tolerated by the patients in the postoperative period. No clinically significant complications were noted during the follow-up period. Control cerebral angiograms or MRAs performed at 7-52 months (mean/ median, 22.3/14 months) revealed occlusion of all aneurysms and fistulas. One patient had an asymptomatic occlusion of the parent artery incidentally noted on 7-month follow-up angiography. A detailed clinical inquiry revealed that contrary to our recommendations, the patient had chosen to stop his antiplatelet medications for approximately 2 weeks following a 3-month CT angiogram that had revealed obliteration of the aneurysm and patency of the parent artery. There was no hemodynamically significant stenosis of the parent artery in any of the remaining patients. Data on patient characteristics and antiplatelet agents are provided in detail in On-line Table 1. Three of 7 patients were hyper-responders to clopidogrel (P2Y12 receptor reaction unit [PRU] of $<60$; On-line Table 1$)$. In these patients, aspirin was stopped and patients were maintained on only clopidogrel for 6 months. After the follow-up angiogram, aspirin was restarted and clopidogrel was discontinued. There were no children with clopidogrel resistance (PRU of $>240$ ).

There was no significant difference in the occurrence of significant adverse effects in patients treated for CCF compared with those with aneurysms ( $P=1.0$; OR, 4 ; 95\% confidence interval, 0.11-136.95).

\section{DISCUSSION}

Pediatric intracranial aneurysms are uncommon $(0.5 \%-4.6 \%$ of all intracranial aneurysms), and there are limited data regarding the optimal treatment method. ${ }^{16-18}$ Saraf et $\mathrm{al}^{19}$ reported that endovascular management is a safe, durable, and effective treatment for pediatric intracranial aneurysms.

Considering the substantial rise in the use of flow diverters among all contemporary endovascular devices in adults, it is expected that these devices will be used with increasing frequency in the pediatric population. There are higher incidences of fusiform and giant aneurysms in the pediatric population. ${ }^{12,18,20}$ Hence, pediatric aneurysms are more likely to be suitable for flow diversion compared with those in adults. However, because there are fundamental differences between intracranial aneurysms in adults and children, it has been proposed that the results of cerebral flow diversion may not be readily applicable to children. ${ }^{11}$ Although endovascular treatment with flow diverters has shown good angiographic results, high complete occlusion rates, ${ }^{21-23}$ and acceptable overall procedure-related morbidity/mortality ${ }^{21}$ in adults, there is a higher risk of unfavorable outcomes in poste- rior circulation aneurysms and large/giant aneurysms, which are more frequently encountered in the pediatric population. ${ }^{21,24}$

The current series is the largest one of pediatric patients treated with flow diverters reported to date. To the best of our knowledge, 15 cases (16 aneurysms) of flow-diverter implantation in children have been reported in the literature, including case reports and 2 series with 3 patients each. ${ }^{2-11}$ The current study reports the youngest patient treated with a flow diverter and reports the use of these devices for the treatment of noniatrogenic intracranial fistula in children for the first time, to our knowledge.

Data on the results of the use of flow diverters in children have been considered positive, and potential pitfalls have been overlooked. All of the previously reported cases, except a case described by Abla et al, ${ }^{9}$ were technically successful and produced good clinical outcomes, and all devices except 1 were patent on follow-up. These reports suggest that flow diversion can be a good alternative for the treatment of challenging pediatric cerebral aneurysms. On the basis of our results, we believe that flow diverters are associated with significant improvement in the endovascular treatment of cerebrovascular diseases. However, several issues still require further clarification.

The first issue is children's growth. The ongoing growth of cerebral vessels in children has been suggested as a potential pitfall by some authors ${ }^{11,25}$ or even as a contraindication for cerebral stent placement or flow diversion in this age group. ${ }^{26}$ Waitzman et $\mathrm{al}^{27}$ showed that cranial growth is rapid during the first year of life, slows markedly in later years, and is almost complete by age 6 . Arat et $\mathrm{al}^{28}$ showed that by 48 months of life, $81 \%-99 \%$ of adult diameters were attained in intracranial arteries; however, only $59 \%$ of adult diameters were attained for the common iliac artery. Later, similar findings regarding children were also reported by He et al. ${ }^{29}$ From a morphometric standpoint, these studies suggest the following: The size range of current intracranial stents or flow diverters is sufficient to cover the pediatric population, and intracranial arterial diameters in children do not undergo striking growth, especially after early childhood. Thus, the implication that stent placement may result in intracranial stenosis or similar effects later in life is not supported by the current literature. Problems associated with femoral access through the significantly smaller iliac/femoral artery diameters in children can be minimized by using long $4 \mathrm{~F}$ introducer sheaths or by direct groin access with $4 \mathrm{~F}$ diagnostic catheters. In one of the patients in the current report, we were able to place a flow diverter through a direct femoral access by using a $4 \mathrm{~F}$ catheter, which is remarkably smaller than a $3 \mathrm{~F}$ sheath. ${ }^{30}$

The second, and more important, issue is our concern about pre-/postprocedural antiplatelet medication protocols used for flow diverters. There is no standard antiplatelet/anticoagulant therapy for children undergoing intracranial placement of vascular scaffolds (ie, stents, stent grafts, or flow diverters). Analyzing the 35 cases reported in the literature in which there is a somewhat detailed description of the placement of cerebral vascular scaffolds in children, we found that antiplatelet administration for endovascular treatment was extremely variable (On-line Table 2). ${ }^{2-11,25,31-43}$ There are neither guidelines published on antiplatelet therapy (APT) in children with cerebrovascular diseases ${ }^{25}$ nor conclusive trials on pediatric APT regimens. ${ }^{44,45}$ Weight- 
based dose calculations extrapolated from an adult dosing of 75 mg per day are not only misleading but also may lead to lifethreatening consequences. ${ }^{45,46}$ A randomized study in children with heart disease showed that clopidogrel doses as low as 0.2 $\mathrm{mg} / \mathrm{kg}$ may be enough to achieve a sufficient therapeutic effect in infants and young children (compared with the approximate dose of $1 \mathrm{mg} / \mathrm{kg}$ used for adults). ${ }^{46}$ Furthermore, the need for agespecific reference ranges for children has been discussed. ${ }^{47}$ On the basis of the referenced reports, we modified our adult regimen of APT (75 mg per day of clopidogrel daily and $300 \mathrm{mg}$ of aspirin daily for 6 months, cessation of clopidogrel at 6 months, and administration of $300 \mathrm{mg}$ of aspirin indefinitely). We chose to premedicate our patients with clopidogrel (75 $\mathrm{mg}$ per day for patients of $>45 \mathrm{~kg}, 37.5 \mathrm{mg}$ per day for patients of $<45 \mathrm{~kg}$ ) and aspirin (300 mg per day for patients of $\geq 45 \mathrm{~kg}, 100 \mathrm{mg}$ per day for smaller children) before endovascular treatment. This regimen was based on the assumption that older children would respond to aspirin and clopidogrel as safely as our low-weight adult patients who weigh around $45 \mathrm{~kg}$. For young children, we wanted to reduce the dose.

We had 2 options for clopidogrel dose reduction: giving clopidogrel every other day or breaking the tablet into 2 or 4 pieces. We did not favor the "every-other-day" type of regimen because we were not able to predict the pharmacokinetics with this approach and there was a risk of lower efficacy and stent thrombosis. Instead, we took a risk of a hyper-response and decided to administer a fraction of a tablet. Because breaking the tablet into 4 parts proved unreliable with families, we asked them to give half a tablet per day. For adjusting the aspirin dose, our thinking was similar. We chose to start the older children on a higher dose to avoid thromboembolic events. If the PRU levels were $<60$ on the day of the procedure, aspirin was discontinued for 6 months (until follow-up angiography); it was then restarted as clopidogrel was discontinued. Point-of-care test results for the evaluation of clopidogrel resistance were available for all our patients except 1 (On-line Table 1), compared with 4/35 children with the placement of some form of intracranial stent reported in the literature (On-line Table 2) showing the effectiveness of this protocol. However, the level of antiplatelet response as determined by point-of-care testing was higher than the response reported in adults $^{48}$ and was indicative of lower doses of APT possibly being used to more safely produce the desired antiaggregation.

Routine testing of platelet function has been recommended for APT in children with cardiac disease, ${ }^{49}$ and it may help to prevent excessive platelet inhibition in pediatric cerebrovascular diseases as well. In the pediatric population, aspirin should be used cautiously because of its association with Reye syndrome, which can be life-threatening. ${ }^{50}$ The American Heart Association recommends that aspirin be withheld in children during influenza and chicken pox infections. ${ }^{51}$ The need for life-long antiplatelet therapy is a drawback of flow diverters. We were able to discontinue both aspirin and clopidogrel in one of our patients after 6 months on the basis of the large size of the stented artery (cavernous ICA), enabling complete thrombosis of the aneurysm and patency of the parent artery without any clinical consequences. Bioabsorbable stents have been used for neurovascular diseases to address this problem. ${ }^{52,53}$
Another drawback is related to the delayed events that can occur after the placement of flow diverters. Abla et $\mathrm{al}^{9}$ described the failure of 7 telescopically placed flow diverters in a child; because further endovascular options were diminished, their patient had to undergo a surgical parent artery occlusion with a superficial temporal artery-middle cerebral artery bypass. In addition to this patient, we report a child presenting with occlusion of a giant middle cerebral artery aneurysm and the parent artery at 7-month follow-up. This patient admitted that he discontinued clopidogrel for several weeks between his 3- and 7-month follow-up studies. Similar occlusions have been reported in pediatric patients after intracranial placement of flow diverters or stent grafts. ${ }^{11,54} \mathrm{An}$ other child in this study as well as 1 patient who underwent treatment of a giant basilar artery aneurysm with a Pipeline Embolization Device (PED; Covidien, Irvine, California) (this patient was not included in our analysis because he was not previously treated by us; however, he is currently under our follow-up) had TIA-like symptoms and no abnormalities on diffusion-weighted MR imaging performed just after the event. These symptoms occurred after short-term interruption of antiplatelet medications and resolved after the medications were resumed. Additionally, one of our patients showed a delayed spontaneous change in the configuration of his flow diverter, necessitating a second endovascular intervention. These cases suggest that delayed findings or events may be observed in children after flow diversion, similar to those observed in adults. Children will have to live with the consequences of these delayed events for the remainder of their lives.

Fortunately, the treatment of aneurysms with flow diverters results in reduced total radiation doses, fluoroscopy time, and contrast medium administration with respect to standard coiling techniques. ${ }^{55}$ Follow-up imaging after flow diversion can be performed without radiation by MR imaging to rule out aneurysm recurrence. ${ }^{56}$ The reduction of the radiation dose is critical in pediatric interventional procedures. ${ }^{25,55,57}$

Our results point to problems associated with the use of flow diverters in the pediatric population and antiplatelet regimens for children. However, there are limitations to our study. The main limitations of this series are the low number patients, the heterogeneity of pathologic conditions (fistulas and aneurysms), and the variations in technique (such as placement of different flow diverters, placement of scaffolding stents). In addition, a longer follow-up duration is preferable in children. Because the number of pediatric patients amenable to flow diverters is limited, it is not possible to draw firm conclusions on pediatric flow diversion based on single-center studies. Multicenter studies and registries may be helpful in addressing the benefits and limitations of flow diverters in children more reliably.

\section{CONCLUSIONS}

In this study, we retrospectively analyzed our data to identify pediatric patients who were treated with the implantation of flowdiverter stents. Five patients with aneurysms and 2 patients with CCFs were successfully treated with flow diverters. This case series suggests that treatment with flow diverters is an option for complex pediatric intracranial aneurysms and CCFs; however, the long-term efficacy, patency, and risk of long-term APT are yet to be clarified through additional studies. With further refinement 
in flow-diverter technology, flow diversion is very likely to be used more frequently in children.

\section{REFERENCES}

1. D’Urso PI, Lanzino G, Cloft HJ, et al. Flow diversion for intracranial aneurysms: a review. Stroke 2011;42:2363-68 CrossRef Medline

2. Takemoto K, Tateshima S, Golshan A, et al. Endovascular treatment of pediatric intracranial aneurysms: a retrospective study of 35 aneurysms. J Neurointerv Surg 2014;6:432-38 CrossRef Medline

3. Appelboom G, Kadri K, Hassan F, et al. Infectious aneurysm of the cavernous carotid artery in a child treated with a new-generation of flow-diverting stent graft: case report. Neurosurgery 2010;66: E623-24 CrossRef Medline

4. Burrows AM, Zipfel G, Lanzino G. Treatment of a pediatric recurrent fusiform middle cerebral artery (MCA) aneurysm with a flow diverter. J Neurointerv Surg 2013;5:e47 CrossRef Medline

5. Lubicz B, Collignon L, Raphaeli G, et al. Flow-diverter stent for the endovascular treatment of intracranial aneurysms: a prospective study in 29 patients with 34 aneurysms. Stroke 2010;41:2247-53 CrossRef Medline

6. Zarzecka A, Gory B, Turjman F. Implantation of two flow diverter devices in a child with a giant, fusiform vertebral artery aneurysm: case report. Pediatr Neurol 2014;50:185-87 CrossRef Medline

7. Navarro R, Brown BL, Beier A, et al. Flow diversion for complex intracranial aneurysms in young children. J Neurosurg Pediatr 2015; 15:276-81 CrossRef Medline

8. Ikeda DS, Marlin ES, Shaw A, et al. Successful endovascular reconstruction of a recurrent giant middle cerebral artery aneurysm with multiple telescoping flow diverters in a pediatric patient. Pediatr Neurosurg 2015;50:88-93 CrossRef Medline

9. Abla AA, Zaidi HA, Crowley RW, et al. Optic chiasm compression from mass effect and thrombus formation following unsuccessful treatment of a giant supraclinoid ICA aneurysm with the Pipeline device: open surgical bailout with STA-MCA bypass and parent vessel occlusion. J Neurosurg Pediatr 2014;14:31-37 CrossRef Medline

10. Kan P, Mokin M, Puri AS, et al. Successful treatment of a giant pediatric fusiform basilar trunk aneurysm with Surpass flow diverter. J Neurointerv Surg 2016;8:e23 CrossRef Medline

11. Vargas SA, Diaz C, Herrera DA, et al. Intracranial aneurysms in children: the role of stenting and flow-diversion. J Neuroimaging 2016;26:41-45 CrossRef Medline

12. Lonjon M, Pennes F, Sedat J, et al. Epidemiology, genetic, natural history and clinical presentation of giant cerebral aneurysms. Neurochirurgie 2015;61:361-65 CrossRef Medline

13. Gurkas E, Kaya T, Daglioglu E, et al. Silk device for the treatment of intracranial aneurysms, part 1: periprocedural results, technical aspects and learning curve. Turk Neurosurg 2016;26:525-32 CrossRef Medline

14. De Vries J, Boogaarts J, Van Norden A, et al. New generation of flow diverter (Surpass) for unruptured intracranial aneurysms: a prospective single-center study in 37 patients. Stroke 2013;44:1567-77 CrossRef Medline

15. Derakhshani S, Rosa S, Low S, et al. Early and late postoperative changes in the flow diverter's intra arterial morphology that can have significant consequences (the womble nose effect). Interv Neuroradiol 2013;19(suppl 1):185-87

16. Hetts SW, Narvid J, Sanai N, et al. Intracranial aneurysms in childhood: 27-year single-institution experience. AJNR Am J Neuroradiol 2009;30:1315-24 CrossRef Medline

17. Mehrotra A, Nair AP, Das KK, et al. Clinical and radiological profiles and outcomes in pediatric patients with intracranial aneurysms. J Neurosurg Pediatr 2012;10:340-46 CrossRef Medline

18. Jian BJ, Hetts SW, Lawton MT, et al. Pediatric intracranial aneurysms. Neurosurg Clin N Am 2010;21:491-501 CrossRef Medline

19. Saraf R, Shrivastava M, Siddhartha W, et al. Intracranial pediatric aneurysms: endovascular treatment and its outcome. J Neurosurg Pediatr 2012;10:230-40 CrossRef Medline
20. Krings T, Geibprasert S, terBrugge KG. Pathomechanisms and treatment of pediatric aneurysms. Childs Nerv Syst 2010;26:1309-18 CrossRef Medline

21. Brinjikji W, Murad MH, Lanzino G, et al. Endovascular treatment of intracranial aneurysms with flow diverters: a meta-analysis. Stroke 2013;44:442-47 CrossRef Medline

22. Shankar JJ, Tampieri D, Iancu D, et al. SILK flow diverter for complex intracranial aneurysms: a Canadian registry. J Neurointerv Surg 2016;8:273-78 CrossRef Medline

23. Chalouhi N, Tjoumakaris S, Starke RM, et al. Comparison of flow diversion and coiling in large unruptured intracranial saccular aneurysms. Stroke 2013;44:2150-54 CrossRef Medline

24. Kaya T, Daglioglu E, Gurkas E, et al. Silk device for the treatment of intracranial aneurysms, part 2: factors related to clinical and angiographic outcome. Turk Neurosurg 2016;26:533-37 CrossRef Medline

25. Requejo F, Lipsich F, Jaimovich R, et al. Neurovascular stents in pediatric population. Childs Nerv Syst 2016;32:505-09 CrossRef Medline

26. Arnold M, Steinlin M, Baumann A, et al. Thrombolysis in childhood stroke: report of 2 cases and review of the literature. Stroke 2009;40: 801-07 Medline

27. Waitzman AA, Posnick JC, Armstrong DC, et al. Craniofacial skeletal measurements based on computed tomography, part II: normal values and growth trends. Cleft Palate Craniofac J 1992;29:118-28 Medline

28. Arat YO, Arat A, Aydin K. Angiographic morphometry of internal carotid artery circulation in Turkish children. Turk Neurosurg 2015; 25:608-16 CrossRef Medline

29. He L, Ladner TR, Pruthi S, et al. Rule of 5: angiographic diameters of cervicocerebral arteries in children and compatibility with adult neurointerventional devices. J Neurointerv Surg 2015 Nov 6. [Epub ahead of print] Medline

30. Sanon S, Gulati R. Slender approach and sheathless techniques. Intervent Cardiol Clin 2015;4:161-66 CrossRef

31. Cohen JE, Ferrario A, Ceratto R, et al. Reconstructive endovascular approach for a cavernous aneurysm in infancy. Neurol Res 2003;25: 492-96 Medline

32. Chandela S, Alzate J, Sen C, et al. Treatment of a complex posterior fossa aneurysm in a child using side-to-side posterior inferior cerebellar artery-posterior inferior cerebellar artery bypass. J Neurosurg Pediatr 2008;1:79-82 Medline

33. Crowley RW, Evans AJ, Kassell NF, et al. Endovascular treatment of a fusiform basilar artery aneurysm using multiple "in-stent stents": technical note. J Neurosurg Pediatr 2009;3:496-500 Medline

34. Wilms G, Buyse G, van Loon J, et al. Treatment of a giant basilar artery aneurysm with a bridging stent and subsequent coil occlusion of the stent: case report. Neurosurgery 2010;67:E510-11 CrossRef Medline

35. Fontela PS, Tampieri D, Atkinson JD, et al. Posttraumatic pseudoaneurysm of the intracavernous internal carotid artery presenting with massive epistaxis. Pediatr Crit Care Med 2006;7:260-62 Medline

36. Gupta V, Jain V, Mathuria SN, et al. Endovascular treatment of a mycotic intracavernous carotid artery aneurysm using a stent graft. Interv Neuroradiol 2013;19:313-19 Medline

37. Gralla J, Brekenfeld C, Schmidli J, et al. Internal carotid artery aneurysm with life-threatening hemorrhages in a pediatric patient: endovascular treatment options. J Endovasc Ther 2004;11:734-38 Medline

38. Komiyama M, Yoshimura M, Honnda $\mathrm{Y}$, et al. Acute basilar artery dissection treated by emergency stenting in a 13-year-old boy. $\mathrm{Pe}$ diatr Neurosurg 2005;41:318-22 Medline

39. Lai YJ, Chang FC, Lin CJ, et al. Endovascular therapy in pediatric intracranial carotid artery dissection. Pediatr Neurol 2010;42: 291-94 CrossRef Medline

40. Lee JY, Kwon BJ, Kang HS, et al. Subarachnoid hemorrhage from a dissecting aneurysm of the posterior cerebral artery in a child: re- 
bleeding after stent-assisted coiling followed by stent-within-stent technique. J Korean Neurosurg Soc 2011;49:134-38 CrossRef Medline

41. Binning MJ, Khalessi AA, Siddiqui AH, et al. Stent placement for the treatment of a symptomatic intracranial arterial dissection in an adolescent. J Neurosurg Pediatr 2010;6:154-58 CrossRef Medline

42. Ogilvy CS, Tawk RG, Mokin M, et al. Stent-assisted coiling treatment of pediatric traumatic pseudoaneurysm resulting from tumor surgery. Pediatr Neurosurg 2011;47:442-48 CrossRef Medline

43. Savastano LE, Chaudhary N, Gemmete JJ, et al. Stent-assisted coil embolization of a symptomatic middle cerebral artery aneurysm in an infant. J Neurosurg Pediatr 2014;14:550-54 CrossRef Medline

44. Bassareo PP, Fanos V, Iacovidou N, et al. Antiplatelet therapy in children: why so different from adults? Curr Pharm Des 2012;18: 3019-33 CrossRef Medline

45. Mertens L, Eyskens B, Boshoff D, et al. Safety and efficacy of clopidogrel in children with heart disease. J Pediatr 2008;153:61-64 Medline

46. Li JS, Yow E, Berezny KY, et al; PICOLO Investigators. Dosing of clopidogrel for platelet inhibition in infants and young children: primary results of the platelet inhibition in children on clopidogrel (PICOLO) trial. Circulation 2008;117:553-59 CrossRef Medline

47. Yip C, Linden MD, Attard C, et al. Platelets from children are hyperresponsive to activation by thrombin receptor activator peptide and adenosine diphosphate compared to platelets from adults. $\mathrm{Br} \mathrm{J}$ Haematol 2015;168:526-32 CrossRef Medline

48. Delgado Almandoz JE, Kadkhodayan Y, Crandall BM, et al. Variability in initial response to standard clopidogrel therapy, delayed conversion to clopidogrel hyper-response, and associated thromboembolic and hemorrhagic complications in patients undergoing endovascular treatment of unruptured cerebral aneurysms. J Neurointerv Surg 2014;6:767-73 CrossRef Medline

49. Hanke CA, Stiller B, Nakamura L, et al. Prophylactic use of clopidogrel in paediatric cardiac patients. Klin Padiatr 2012;224:166-69 CrossRef Medline

50. Selves A, Ruiz S, Crognier L, et al. Aspirin and its danger: Reye syn- drome in young adult [in French]. Ann Fr Anesth Reanim 2013;32: 814-16 CrossRef Medline

51. Giglia TM, Massicotte MP, Tweddell JS, et al; American Heart Association Congenital Heart Defects Committee of the Council on Cardiovascular Disease in the Young, Council on Cardiovascular and Stroke Nursing, Council on Epidemiology and Prevention, and Stroke Council. Prevention and treatment of thrombosis in pediatric and congenital heart disease: a scientific statement from the American Heart Association. Circulation 2013;128:2622-703 CrossRef Medline

52. Arat A, Daglioglu E, Akmangit I. Neurovascular applications of bioabsorbable stents. Interv Neuroradiol 2015;21;(suppl 1):181

53. Wang K, Yuan S, Zhang X, et al. Biodegradable flow-diverting device for the treatment of intracranial aneurysm: short-term results of a rabbit experiment. Neuroradiology 2013;55:621-28 CrossRef Medline

54. Özkan Arat Y, Arat A, Aydın K. Cerebrovascular complications of transorbital penetrating intracranial injuries. Ulus Travma Acil Cerrahi Derg 2015;21:271-78 CrossRef Medline

55. Colby GP, Lin LM, Nundkumar N, et al. Radiation dose analysis of large and giant internal carotid artery aneurysm treatment with the Pipeline embolization device versus traditional coiling techniques. J Neurointerv Surg 2015;7:380-84 CrossRef Medline

56. Attali J, Benaissa A, Soize S, et al. Follow-up of intracranial aneurysms treated by flow diverter: comparison of three-dimensional time-of-flight MR angiography (3D-TOF-MRA) and contrast-enhanced MR angiography (CE-MRA) sequences with digital subtraction angiography as the gold standard. J Neurointerv Surg 2016;8: 81-86 CrossRef Medline

57. Johnson C, Martin-Carreras T, Rabinowitz D. Pediatric interventional radiology and dose-reduction techniques. Semin Ultrasound CT MR 2014;35:409-14 CrossRef Medline

58. Halimeh S, Angelis G, Sander A, et al. Multiplate whole blood impedance point of care aggregometry: preliminary reference values in healthy infants, children and adolescents. Klin Padiatr 2010;222: 158-63 CrossRef Medline 